\title{
Enhanced jejunal production of antibodies to Klebsiella and other Enterobacteria in patients with ankylosing spondylitis and rheumatoid arthritis
}

Outi Mäki-Ikola, Roger Hällgren, Lars Kanerud, Nils Feltelius, Lars Knutsson, Kaisa Granfors

National Public Health Institute, Department in Turku, Turku, Finland

O Mäki-Ikola

K Granfors

University Hospital,

Department of

Internal Medicine,

Section of

Rheumatology,

Uppsala, Sweden

R Hällgren

$\mathrm{N}$ Feltelius

Karolinska Institute, Stockholm Söder Hospital, Department of Rheumatology, Stockholm, Sweden

L Kanerud

University Hospital, Department of Surgery, Uppsala, Sweden

Lars Knutsson

Correspondence to: Dr O Mäki-Ikola, National Public Health Institute, Department in Turku, Kiinamyllynkatu 13 ,

SF-20520 Turku, Finland.

Accepted for publication 8 May 1997

\begin{abstract}
Objective-To measure gut immunity directly in jejunal fluid in patients with ankylosing spondylitis (AS) and rheumatoid arthritis (RA).

Methods-Antibodies against three different Enterobacterias were measured in jejunal perfusion fluids (collected by a double balloon perfusion device) of 19 patients with $A S, 14$ patients with $R A$, and 22 healthy controls using enzyme linked immunosorbent assay.

Results-The AS patients had significantly increased jejunal fluid concentrations of IgM, IgG, and IgA class antibodies against Klebsiella pneumoniae, and $\operatorname{Ig} M$ and $\operatorname{IgA}$ class antibodies against Escherichia coli and Proteus mirabilis compared with healthy controls. When compared with the patients with $R A$, the AS patients had higher concentrations of IgA and IgG class antibodies only against $K$ pneumoniae. The RA patients had higher IgM class antibody concentrations against all three studied Enterobacterias, when compared with the healthy controls, suggesting an enhanced mucosal immune response in these patients. A three month treatment with sulphasalazine did not decrease enterobacterial antibody concentrations in the 10 patients with AS.

Conclusion-There is strong direct evidence for an abnormal mucosal humoral immune response particularly to $K$ pneumoniae in patients with AS.
\end{abstract}

(Ann Rheum Dis 1997;56:421-425)

The aetiology of ankylosing spondylitis (AS) is still unknown. ${ }^{1}$ It has been suggested that the Gram negative micro-organism Klebsiella pneumoniae plays an important part in the pathogenesis. Increased faecal carriage of Klebsiella species, as well as increased serum antibody concentrations, especially of immunoglobulin A (IgA), against Klebsiella bacteria in patients with AS have been reported. ${ }^{2-6}$ Furthermore, a decrease has been seen in the concentration of serum IgA class antibodies against $K$ pneumoniae and Escherichia coli during 26 weeks of sulphasalazine treatment. ${ }^{3}$ On the other hand, a quantitative reduction of $K$ pneumoniae responsive $\mathrm{T}$ cells in peripheral blood of AS patients may reflect a defective peripheral $\mathrm{T}$ cell defence in the immune response to Klebsiella. ${ }^{7}$ Furthermore, molecular mimicry between Klebsiella and HLA B27 antigens has been noted. ${ }^{12}$ However, the association between Klebsiella and AS is still a subject of controversy. ${ }^{8}$

Also further evidence for the role for gut and mucosal immune defence mechanisms in the pathogenesis of AS is available. For example, gut permeability has been shown to be increased in patients with AS. ${ }^{9}$ In addition, serum concentrations of total $\operatorname{IgA}$, as well as secretory $\operatorname{IgA}$ and the IgA subclasses have been shown to be persistently raised in patients with AS. ${ }^{10-12}$ This has been interpreted as signs of stimulation of the secretory immune system, perhaps through the gastrointestinal tract, because the intestinal lamina propria harbours more than $80 \%$ of all IgA producing cells. ${ }^{13}$ Also an increased IgA concentration in parotid saliva in active AS has been taken as evidence of mucosal immune stimulation in AS. ${ }^{11}$

Intestinal micro-organisms have also been implicated in the aetiology or pathogenesis, or both, of rheumatoid arthritis (RA). ${ }^{14}$ A changed gastrointestinal microflora has been demonstrated $^{15}$ and evidence of jejunal bacterial overgrowth in RA have been reported. ${ }^{16}$ Futhermore, there are reports showing increased serum antibody concentrations against Proteus mirabilis in RA patients ${ }^{17} 18$ although the relevance of this finding has been questioned. ${ }^{19}$ In similarity with AS, an increased gut permeability has also been observed in $\mathrm{RA}^{20}$ and serum IgA is frequently increased in both diseases. ${ }^{21}$

Recently a double balloon perfusion device was developed, which allows controlled measuring of gut immunity directly in jejunal fluid. ${ }^{22}{ }^{24}$ Using this direct method we have shown that concentrations of total $\operatorname{IgM}, \operatorname{IgA}$, secretory $\operatorname{IgA}$, and secretory component were significantly increased in the jejunal perfusion fluids of 19 AS patients when compared with the healthy controls. ${ }^{25}$ In this study we have analysed the concentrations of $\operatorname{IgM}, \operatorname{IgG}$, and IgA class antibodies against $K$ pneumoniae, $E$ coli, and $P$ mirabilis in the jejunal perfusion fluids of those 19 patients with AS as well as in 14 patients with RA using enzyme linked immunosorbent assay (ELISA); jejunal perfusion fluids from 22 healthy controls served as controls. The effect of three month 
sulphasalazine treatment on the antibody concentrations of the AS patients was also analysed.

\section{Methods}

PATIENTS

We studied 19 male patients with AS diagnosed according to the New York criteria, ${ }^{26}$ with mean age of 36 years (range 21-66) and the mean duration of the disease of 11 years (range 1-25). Furthermore, 14 patients with RA diagnosed according to the ARA criteria ${ }^{27}$ were studied. Their mean age was 50 years (range 26-70) and the mean duration of disease 10 years (range 9 months-30 years). Twenty two healthy subjects with mean age of 29 years (range 23-39) served as controls. The RA patients suffered from active disease as defined by the presence of at least two of the following three criteria: duration of morning stiffness $\geq 60$ minutes, tenderness or swelling, or both, of $\geq$ six joints, and a Westergren sedimentation rate $\geq 30 \mathrm{~mm} \mathrm{1st} \mathrm{h}$. The majority of patients were treated with non-steroidal anti-inflammatory drugs (NSAIDs); in all but two this treatment was withdrawn for three days or more before intestinal perfusion was performed. Ten of the AS patients were reinvestigated after treatment with sulphasalazine for three months: the dose of sulphasalazine was increased as described earlier ${ }^{28}$ to a final dose of $2-3 \mathrm{~g} /$ day. The disease activity of the AS patients was determined, before and after sulphasalazine treatment, by the following clinical variables (reference values in parentheses): chest expansion corresponding to 4 th intercostal space $(>40$ $\mathrm{mm})$; Schrober's test (> $40 \mathrm{~mm}$ ); duration of morning stiffness in minutes; number of painful and swollen joints excluding lumbar spine; presence of sacroiliac pain; physician's global assessment; erythrocyte sedimentation rate (ESR) according to Westergren $(<15 \mathrm{~mm} 1 \mathrm{st}$ h) and haptoglobin $(0.3-2.0 \mathrm{~g} / \mathrm{l})$.

\section{JEJUNAL PERFUSION FLUIDS}

A segment of intestine was perfused as described earlier in detail ${ }^{22}$ by a small diameter tube that was $175 \mathrm{~cm}$ long and contained six channels. The insertion of the tube, gastric drainage, inflation of the balloons, and rinsing of the closed intestinal segment were performed as described. ${ }^{22}{ }^{14} \mathrm{C}$-labelled polyethylene glycol was used as a volume marker and phenolsulphonphatalein (phenol red) as a marker of the patency of the proximal balloon. The recovery of the volume marker was on average $91(5) \%$ (mean (SD)) in patients with AS, $86(10) \%$ in patients with RA, and $89(6) \%$ in healthy controls. Proximal leakage into the jejunal segment, as tested by the appearance of phenol red in the perfusion fluid, was less than $2 \%$ of the amount infused in the stomach. The perfusion fluids were collected on ice, centrifuged in cold conditions at $2500 \mathrm{~g}$, and frozen in samples of $2 \mathrm{ml}$ until analysis.

ANTIGENS FOR ELISA

Sodium dodecyl sulphate (SDS) extracts of $K$ pneumoniae strain 21, 43, and ATCC 27736 were used. Antibodies raised against the strains 21 and 43 have been shown to lyse the HLA-B27 positive lymphocytes of about $80 \%$ of patients with AS, $60 \%$ of those with Reiter's syndrome or B27 positive asymmetrical peripheral arthritis, and $20 \%$ of patients with B27 positive uveitis; the B27 positive lymphocytes of clinically normal people were not lysed. ${ }^{23}$ The strain ATCC 27736 has been widely used in our earlier studies concerning the pathogenesis of AS. ${ }^{346}$ E coli and P mirabilis strains were clinical isolates from the Department of Medical Microbiology, Turku University, Turku, Finland. The antigen extracts were prepared as previously described. ${ }^{4}$

ELISA FOR ANTIBODIES AGAINST $K$ PNEUMONIAE, $E$ COLI, AND P MIRABILIS

IgM, IgG, and IgA class antibodies against $K$ pneumoniae, $E$ coli, and $P$ mirabilis were analysed principally as we have described earlier. $^{34}$ The polystyrene microtitre plates (Nunc, Roskilde, Denmark) were coated with SDS-extracts of K pneumoniae, E coli or P mirabilis in phosphate buffered saline (PBS; 0.1 $\mathrm{mol} / \mathrm{l}, \mathrm{pH} 7.5 ; 100 \mu \mathrm{l} /$ well $)$ overnight at $37^{\circ} \mathrm{C}$. The plates were saturated with $1 \%$ normal sheep serum in PBS (NSS-PBS; $100 \mu \mathrm{l} /$ well). Patient jejunal perfusion fluid samples at $1: 5$ dilution ( $75 \mu \mathrm{l} /$ well; two replicate wells) were incubated on the plates for two hours at $37^{\circ} \mathrm{C}$. Thereafter, $75 \mu \mathrm{l} /$ well of alkaline phosphatase conjugated swine antihuman IgM, IgG or IgA (Orion Diagnostica, Espoo, Finland), diluted $1: 250,1: 500$, and 1:250, respectively, were incubated on the plates overnight at room temperature. Fresh $p$-nitrophenyl phosphate in diethanolamine- $\mathrm{MgCl}_{2}$ buffer solution (1 $\mathrm{mg} / \mathrm{ml}$; Orion Diagnostica) was added, incubated for 30 minutes at $37^{\circ} \mathrm{C}$ and the reaction stopped with $1 \mathrm{M}$ sodium hydroxide. The optical density was measured with a Titertek Multiscan Photometer (Labsystems, Helsinki, Finland) at a wavelength of $405 \mathrm{~nm}$.

STATISTICAL ANALYSIS

The mean concentrations of antibodies in different groups were compared with the Student's $t$ test. The effect of sulphasalazine on antibody concentrations and on clinical and laboratory parameters within group was analysed using the paired Student's $t$ test. Differences were considered significant when $p<$ 0.05 .

\section{Results}

ENTEROBACTERIAL ANTIBODY CONCENTRATIONS IN JEJUNAL PERFUSION FLUIDS FROM AS PATIENTS, RA PATIENTS, AND HEALTHY CONTROLS

Kpneumoniae

The AS patients had statistically significantly higher concentrations of jejunal IgM, IgG, and IgA class antibodies against $K$ pneumoniae 43 and 21 , and $\operatorname{IgM}$ and $\operatorname{IgA}$ class antibodies against $K$ pneumoniae 27736, when compared with the healthy controls. When compared with the RA patients the AS patients had higher concentrations of IgA and IgG class antibodies against $K$ pneumoniae 21 , as well as 


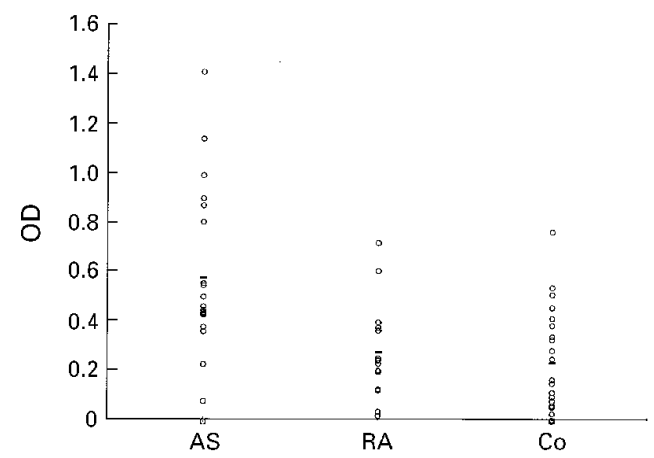

Figure 1 Klebsiella pneumoniae 27736 specific IgA class antibody concentrations in jejunal perfusion fluid samples of patients with ankylosing spondylitis (AS) and rheumatoid arthritis (RA) and of healthy controls (Co). Optical densities (OD) at $405 \mathrm{~nm}$ are given. Horizontal lines represent mean values of all patients or controls.

higher IgG class concentration with the $K$ pneumoniae 43 and higher IgA class concentration with the Kpneumoniae 27736 (fig 1, table 1).

The RA patients had higher concentrations of IgM class antibodies against all three Klebsiella serotypes when compared with the healthy controls (table 1).

\section{$E$ coli and $P$ mirabilis}

The AS patients had statistically significantly higher jejunal IgM and IgA class antibody concentrations against both $E$ coli and $P$ mirabilis when compared with the healthy controls; no statistically significant differences were seen between the patients with AS and RA. When the RA patients were compared with the healthy controls, the patients had higher IgM class jejunal antibody concentrations against $P$ mirabilis (table 1).

EFFECT OF SULPHASALAZINE TREATMENT ON THE ENTEROBACTERIAL ANTIBODY CONCENTRATIONS IN JEJUNAL PERFUSION FLUIDS

No statistically significant changes were seen in the jejunal antibody concentrations of AS patients of IgM, IgG or IgA classes against $K$ pneumoniae 27736,21 , or 43 , nor against $E$ coli or $P$ mirabilis after the three month treatment

Table 1 Enterobacterial antibody concentrations in jejunal perfusion fluids of patients with ankylosing spondylitis ( $A S)$, rheumatoid arthritis $(R A)$, and healthy controls

\begin{tabular}{lllr}
\hline Antibodies against & $\begin{array}{l}\text { Patients with AS } \\
(n=19) \text { mean }(S D)\end{array}$ & $\begin{array}{l}\text { Patients with } R A \\
(n=22) \text { mean }(S D)\end{array}$ & $\begin{array}{l}\text { Healthy controls } \\
(n=22) \text { mean }(S D)\end{array}$ \\
\hline K pneumoniae 27736 & $0.256(0.185)^{\mathrm{A}}$ & $0.288(0.204)^{\mathrm{B}}$ & $0.149(0.075)$ \\
$\quad$ IgM & $0.572(0.360)^{\mathrm{D}, \mathrm{G}}$ & $0.271(0.201)$ & $0.227(0.209)$ \\
IgA & $0.148(0.268)$ & $0.083(0.100)$ & $0.123(0.088)$ \\
IgG & $0.077(0.064)^{\mathrm{D}}$ & $0.053(0.054)^{\mathrm{B}}$ & $0.017(0.021)$ \\
K pneumoniae 43 & $0.160(0.146)^{\mathrm{C}}$ & $0.082(0.078)$ & $0.060(0.044)$ \\
IgM & $0.016(0.043)^{\mathrm{B}, \mathrm{F}}$ & $-0.016(0.036)$ & $-0.014(0.022)$ \\
IgA & $0.129(0.188)^{\mathrm{A}}$ & $0.167(0.109)^{\mathrm{E}}$ & $0.032(0.042)$ \\
IgG & $0.261(0.155)^{\mathrm{D}, \mathrm{F}}$ & $0.134(0.122)$ & $0.122(0.087)$ \\
K pneumoniae 21 & $0.116(0.054)^{\mathrm{B}, \mathrm{I}}$ & $0.028(0.049)$ & $0.015(0.037)$ \\
IgM & $0.263(0.217)^{\mathrm{C}}$ & $0.205(0.234)$ & $0.108(0.072)$ \\
IgA & $0.551(0.329)^{\mathrm{C}}$ & $0.374(0.269)$ & $0.304(0.167)$ \\
IgG & $0.055(0.056)$ & $0.043(0.037)$ & $0.068(0.055)$ \\
E coli & & $0.103(0.088)^{\mathrm{C}}$ & $0.037(0.036)$ \\
IgM & $0.086(0.088)^{\mathrm{A}}$ & $0.266(0.209)$ & $0.177(0.114)$ \\
IgA & $0.312(0.249)^{\mathrm{A}}$ & $0.036(0.040)$ & $0.029(0.026)$ \\
IgG & $0.031(0.038)$ & & \\
Proteus mirabilis & IgM & &
\end{tabular}

Mean (SD) of the absorbance values at wavelength $405 \mathrm{~nm}$ are given. $\mathrm{n}$, Number of patients. $\mathrm{p} \leq 0.05^{\mathrm{A}}, 0.01^{\mathrm{B}}, 0.005^{\mathrm{C}}, 0.001^{\mathrm{D}}, 0.0001^{\mathrm{E}}$, when compared with healthy controls. $\mathrm{p} \leq 0.05^{\mathrm{F}}, 0.01^{\mathrm{G}}$ $0.005^{\mathrm{H}}, 0.0001^{\mathrm{I}}$ when compared with rheumatoid arthritis. with sulphasalazine. The clinical and laboratory parameters that were evaluated showed a significant reduction of the laboratory inflammatory activity (mean $($ SEM $)$ ); ESR was before and after treatment 49 (10) $\mathrm{mm} 1 \mathrm{st} \mathrm{h}$ and 28 (11) $\mathrm{mm} 1 \mathrm{st} \mathrm{h}$, respectively, and haptoglobin was $3.9(0.4) \mathrm{g} / \mathrm{l}$ and 2.9 (0.4) g/l, respectively. Significant improvement of some clinical variables was also noted; thorax expansion was before and after treatment $3.3(0.4) \mathrm{mm}$ and $4.5(0.4)$ $\mathrm{mm}$, respectively, and the number of peripheral synovitis was $1.5(0.7)$ and 0.6 (0.4), respectively. Schrober's test and morning stiffness were not significantly improved.

\section{Discussion}

In this study we have, for the first time, found direct evidence for an abnormal mucosal humoral immune response particularly to $K$ pneumoniae in patients with AS. We found increased antibody concentrations of $\operatorname{IgM}$, IgG, and IgA classes against K pneumoniae, and to a smaller extent of $\operatorname{IgM}$ and $\operatorname{IgA}$ classes against $E$ coli and $P$ mirabilis in jejunal perfusion fluids of patients with AS when compared with healthy controls. More importantly, when compared with the patients with RA the IgG and IgA class jejunal antibody concentrations were significantly higher only against $K$ pneumoniae in patients with AS. Thus, one part of the recently observed increases in concentrations of total IgM, IgA, secretory IgA, and secretory component in jejunal fluids of the AS patients ${ }^{25}$ should represent Klebsiella specific antibodies. A small part of these earlier detected increases in the total jejunal antibody concentrations may result from $E$ coli and $P$ mirabilis specific antibodies; however, these antibody values were clearly not as significantly and noticeably increased as those against $K$ pneumoniae and hence may reflect only cross reactions with Klebsiella, as Gram negative bacteria are known to share common antigens.

The present findings corroborate with variety of earlier findings suggesting a role for gut and mucosal immune defence mechanisms and especially for $K$ pneumoniae microorganisms in the pathogenesis of AS. ${ }^{259-1229}$ Also our earlier studies showing considerably increased K pneumoniae specific IgA class antibody concentrations in serum samples of AS patients are indirectly confirmed with the present findings. ${ }^{36}$

The presence of increased enterobacterial antibody concentations in jejunal perfusion fluids may refer to infection or inflammation in the gut in patients with AS. In patients with AS both ileal and colonic mucosa show often macroscopic and microscopic signs of inflammation, which may resemble an early form of Crohn's disease..$^{30}$ The acute inflammation in both ileal and colonic mucosa in AS has been shown to be associated with an increase of $\operatorname{IgA}$ and IgG producing cells, and the chronic inflammation with an increase not only of $\operatorname{IgA}$ and IgG, but also of IgM producing cells. ${ }^{32}$ As local antigens stimulate a local immunocyte reaction in the gut, the present findings of increased K pneumoniae specific antibody con- 
centrations of all IgM, IgG, and IgA classes are in line with the finding that gut inflammation in AS is mostly of chronic type. ${ }^{30}$

Although considerable scepticism can be raised on the role of Klebsiella $s p$ in the pathogenesis of $\mathrm{AS},{ }^{8}$ it is intriguing to speculate what are the mechanisms by which Klebsiella bacteria or the antibodies evoked against them, or both, might produce the lesions of the disease. Klebsiella infection in the gut may be a causative factor for the previously described enhanced permeability of the gut in patients with $\mathrm{AS},{ }^{9}$ similar to that seen after Yersinia enteritis. ${ }^{33}$ This could then allow certain antigenic material, such as Klebsiella lipopolysaccharide, to pass through mucosa into circulation. Correspondingly, in addition to increased jejunal antibody production persisting serum antibody concentrations against Klebsiella in $\mathrm{AS}^{2-6}$ and similarily against specific arthritis triggering microbes in reactive arthritis, $^{34}$ are detected. If the mechanisms for both AS and reactive arthritis are similar, microbial antigens, such as Klebsiella lipopolysaccharide, are transported into the sites of inflammation - that is, axial as well as peripheral joints of these patients. After this, joint complications are initiated according to, for example, molecular mimicry theory, ${ }^{2}$ or by yet unknown mechanism, similarly to that seen in reactive arthritis. ${ }^{34}$

Although the disease activity measured by clinical and laboratory parameters in the present AS patients improved significantly during the three month treatment with sulphasalazine,${ }^{25}$ we did not find any significant changes in the Enterobacterial antibody concentrations during the treatment. This may be against the direct role of Klebsiella in determining the flare of pre-existing disease. However, in another study using the same perfusion technique the concentrations of total jejunal $\operatorname{IgM}$, IgA, secretory IgA, and secretory component revealed statistically significant decreases during the treatment. ${ }^{25}$ Furthermore, we have recently shown in another AS patient population that Enterobacterial antibody concentrations in serum samples did decrease during the 26 week sulphasalazine treatment. ${ }^{3}$ Thus, the treatment period in the present study may have been too short to significantly decrease the jejunal perfusion fluid antibody concentrations. Moreover, it was recently shown that sulphasalazine excerts inhibitory effect only on systemic immunoglobulin production, whereas no effects on mucosal immunoglobulin production are observed..$^{21}$ It is also possible that the clinical effect of sulphasalazine is mediated by other mechanisms than reduction of antibody production, for example by modifying cytokine or granulocyte protein release.

Patients with RA have previously been shown to possess increased serum antibody concentrations against $P$ mirabilis. ${ }^{17}{ }^{18}$ In our study the patients with RA had higher IgM class jejunal perfusion fluid antibody concentrations against all of the studied Enterobacteria when compared with the healthy controls, suggesting an enhanced mucosal immune response in RA. The overall increased antibacterial antibody concentrations may in part reflect cross reactivity between different Gram negative bacterial species and do not exclude a specific role for $P$ mirabilis in RA. A possibility is, however, that the gut mucosa in RA by some reason is activated and that the increased antibacterial antibody values mirror a polyclonal B cell activation as recent results show a significant increase in total IgM in RA jejunal perfusion fluid (Kanerud et al, unpublished data). Different kinds of stimuli of the gastrointestinal mucosa do not often cause IgM production. The recently reported increased expression of heat shock protein 60 in jejunal epithelium in untreated RA patients ${ }^{15}$ brings further evidence for this hypothesis. Furthermore, an interference on the antibody measurements of rheumatoid factors (RF) present in perfusion fluid does not seem likely, as the perfusion fluid concentrations of IgA-RF were not different in healthy controls, AS, or RA patients, and were approximately $0.3 \%$ of the upper normal serum concentration for IgA-RF (data not shown). The perfusion fluid concentrations of IgM-RF were increased about two times in RA patients compared with healthy controls and AS patients. However, the highest perfusion fluid concentration of IgM-RF in RA patients was only $0.8 \%$ of the upper normal serum value for IgM-RF.

It cannot be ruled out that use of NSAIDs in our patients may have had an influence on antibody values because of their effect towards increased gut permeability, ${ }^{35}$ as some of our patients had been taking NSAIDs before perfusion. However, no significant differences were recently seen in the frequency of endoscopic lesions between patients with and without previous NSAID use, ${ }^{30}$ although associations between the use of NSAIDs and endoscopic lesions have been reported. ${ }^{36}$ The finding of increased IgG and IgA class antibody concentrations in AS patients against only $K$ pneumoniae when compared with patients with RA emphasises particularly the role of Kpneumoniae in the pathogenesis of AS. On a contradictory note to this study O'Mahony et $a l^{37}$ did not find any evidence for an increased antibody response against Klebsiella in whole stool lavage fluids of patients with AS.

The jejunal antibody concentrations against the three studied $K$ pneumoniae strains with capsular types 21,30 , and 43 were relatively similarly increased in AS patients. Of the 77 different capsular types of Klebsiella, three (K26, K36 and K50) have been recently associated with HLA B27 positive AS. ${ }^{29}$ Thus, if jejunal antibodies against these capsular types of Klebsiella had been studied specifically, the increases in antibody concentrations might have been even more clear and the findings in the samples of RA patients different. Further studies on this area are hence warranted.

In summary, this report provides direct evidence for an abnormal mucosal humoral immune response particularly to K pneumoniae in patients with AS. This study confirms many 
of the previous serum antibody studies in patients with AS suggesting a role for $K$ pneumoniae in gut and mucosal immune defence mechanisms in the pathogenesis of AS. The final proof has, however, to come by demonstrating direct involvement of bacteria in the pathogenesis, as has been shown in reactive arthritis. $^{34}$ This report also presents further evidence for an abnormal activation of the jejunal mucosa in RA that merits further research.

We thank Erkki Nieminen, M Sc, for help with statistical analyses and Mrs Tiina Lähde for technical assistance. Our study was supported by the Finnish Academy, the Sigrid Juselius Foundation, the Paulo Foundation, the Finnish Cultural Foundation, the Rheumatism Research Foundation, the Swedish Association Against Rheumatism, the King Gustaf V's 80-year Fund, Professor Nanna Svartz' Foundation, the Alex and Eva Wallström's Foundation, the Ulla and Gustaf af Ugglas' Fund, Börje Dahlin's Fund, 'Förenade Liv' Mutual Group Life Assurance Company, Stockholm, Sweden

1 Khan MA. Pathogenesis of ankylosing spondylitis: Recent advances. J Rheumatol 1990;17:7-10.

2 Ebringer A. Ankylosing spondylitis is caused by Klebsiella Rheum Dis Clin North Am 1992;18:105-21.

3 Nissilä M, Lahesmaa R, Leirisalo-Repo M, Lehtinen $K$, Toivanen P, Granfors K. Antibodies to Klebsiella pneumoniae, Escherichia coli and Proteus mirabilis in ankylosing spondylitis: effect of sulfasalazine treatment. J Rheumatol 1994;21:2082-7.

4 Mäki-Ikola O, Lehtinen K, Granfors K, Vainionpää R, Toivanen P. Bacterial antibodies in ankylosing spondylitis. Clin Exp Immunol 1991;84:472-5.

5 Cooper R, Fraser SM, Sturrock RD, Gemmel CG. Raised titres of anti-klebsiella IgA in ankylosing spondylitis, rheumatoid arthritis, and inflammatory bowel disease. BMJ 1988;296:1432-4.

6 Mäki-Ikola O, Lehtinen K, Nissilä $M$, Toivanen P, Granfors K. Klebsiella-specific antibodies of IgA1 and IgA2 subclasses in patients with ankylosing spondylitis. Ann Rheum Dis 1995;54:631-5.

7 Hermann E, Sucke B, Droste U, Meyer zum Büschenfelde $\mathrm{K}-\mathrm{H}$. Klebsiella pneumoniae-reactive T cells in blood and synovial fluid of patients with ankylosing spondylitis. Arthritis Rheum 1995;38:1277-82.

8 Russell AS, Almazor ES. Ankylosing spondylitis is not caused by Klebsiella. Rheum Dis Clin North Am 1992;18:95-104.

9 Smith MD, Gibson RA, Brooks PM. Abnormal bowel permeability in ankylosing spondylitis and rheumatoid permeability in ankylosing spondylitis
arthritis. J Rheumatol 1985;12:299-305.

10 Cowling P, Ebringer R, Ebringer A. Association of inflammation with raised serum IgA in ankylosing spondylitis. Ann Rheum Dis 1980;39:545-9.

11 Calguneri M, Swinburne L, Shinebaum R, Cooke EM, Wright V. Secretory IgA: Immune defence pattern in ankylosing spondylitis and klebsiella. Ann Rheum Dis 1981;40:600-4.

12 Peeters AJ, Daha MR, Smeets TJM, Breedveld FC. Bone marrow IgA and IgA subclass synthesis in ankylosing spondylitis. J Rheumatol 1992;19:751-3.

13 Brandtzaeg P, Halstensen TS, Kett K, Krajci P, Kvale D, Rognum TO, et al. Immunobiology and immunopathology of human gut mucosa: humoral immunity and intraepithelial lymphocytes. Gastroenterology 1989;97:1562-84.

14 Doube A, Collins AJ. Is the gut intrinsically abnormal in rheumatoid arthritis? Ann Rheum Dis 1988;47:617-9.

15 Kanerud L, Scheynius A, Nord C-E, Hafstörm I. Effects of sulphasalazine on gastrointestinal microflora and on mucosal heat shock protein expression in patients with rheumatoid arthritis. Br J Rheumatol 1994;33:1039-48.
16 Henriksson ÅEK, Blomquist L, Nord C-E, Midtvedt T, Uribe A. Small intestinal bacterial overgrowth in patients with rheumatoid arthritis. Ann Rheum Dis 1993;52:503 10

17 Ebringer A, Ptaszynska T, Corbett M, Wilson C, Macafee Y, Avakian $\mathrm{H}$, et al. Antibodies to Proteus in rheumatoid arthritis. Lancet 1985;ii:305-7.

18 Deighton CM, Gray JW, Bint AJ, Walker DJ. Anti-Proteus antibodies in rheumatoid arthritis same-sexed sibships. Br J Rheumatol 1992;31:241-5.

19 McDonagh J, Gray J, Sykes H, Walker DJ, Bint AJ, Deighton CM. Anti-Proteus antibodies and Proteus organisms in rheumatoid arthritis: a clinical study. $\mathrm{Br} \mathrm{J}$ Rheumatol 1994;33:32-5.

20 Jenkins RT, Rooney PJ, Jones DB, Bienenstock J, Goodacre RL. Increased intestinal permeability in patients with rheumatoid arthritis: A side-effect of oral nonsteroidal anti-inflammatory drug therapy? Br J Rheumatol 1987; 26:103-7.

21 Kanerud L, Norhagen-Engstrm G, Tarkowski A. Evidence for differential effects of sulphasalazine on systemic and mucosal immunity in rheumatoid arthritis. Ann Rheum Dis 1995;54:256-62.

22 Knutson L, Hällgren R, Odlind B. A new technique for segmental jejunal perfusion in man. Am J Gastroenterol 1989;84:1278-84

23 Geczy AF, Alexander K, Bashir HV, Edmonds JP, Upfold L, Sullivan J. HLA-B27, Klebsiella and ankylosing spondylitis: biological and chemical studies. Immunol Rev 1983;70:23-50.

24 Ahrenstedt Ö, Knutson L, Nilsson B, Nilsson-Ekdahl K, Odlind B, Hällgren R. Enhanced local production of complement components in the small intestine of patients with Crohn's disease. N Engl J Med 1990;332:1345-9.

25 Feltelius N, Hvatum M, Brandtzaeg P, Knutson L, Hällgren $\mathrm{R}$. Increased jejunal secretory IgA and IgM in ankylosing spondylitis: normalization after treatment with sulfasalazine. J Rheumatol 1994;21:2076-81.

26 Bennet PH, Wood PHN. Population studies of the rheumatic diseases. Amsterdam: Excerpta Medica, 1968: 456-7

27 Arnett FC, Edworthy SM, Bloch DA, McShane DJ, Fries $\mathrm{JF}$, Cooper NS, et al. The American Rheumatism Association 1987 revised criteria for the classification of rheumatoid arthritis. Arthritis Rheum 1988;31:315-24.

28 Feltelius N, Hällgren R. Sulphasalazine in ankylosing spondylitis. Ann Rheum Dis 1986;45:396-9.

29 Sahly H, Kekow J, Podschun R, Schaff M, Gross WL, Ullmann U. Comparison of the antibody responses to the 77 Klebsiella capsular types in ankylosing spondylitis and various rheumatic diseases. Infect Immun 1994;62:483843.

30 Leirisalo-Repo M, Turunen U, Stenman S, Helenius P, Seppälä K. High frequency of silent inflammatory bowel disease in spondyloarthropathy. Arthritis Rheum 1994; 37:23-31.

31 Mielants H, Veys EM. The gut in the spondyloarthropathies. J Rheumatol 1990;17:7-10.

32 Cuvelier C, Mielants H, De Vos M, Veys E, Roels H. Immunoglobulin containing cells in terminal ileum and colorectum of patients with arthritis related gut inflammation. Gut 1988;29:916-25.

33 Lahesmaa-Rantala R, Magnusson KE, Granfors K, Leino $\mathrm{R}$, Sundqvist $\mathrm{T}$, Toivanen A. Intestinal permeability in patients with yersinia-triggered reactive arthritis. Ann Rheum Dis 1991;50:91-4.

34 Mäki-Ikola O, Granfors K. Salmonella-triggered reactive arthritis. Lancet 1992;339:1096-8.

35 O'Mahony S, Ferguson A. Small intestinal mucosal protection mechanisms and their importance in rheumatology. Ann Rheum Dis 1991;50:331-6.

36 Morris AJ, Howden CW, Robertson C, Duncan A, Torley $\mathrm{H}$, Sturrock RD, et al. Increased intestinal permeability in ankylosing spondylitis: primary lesion or drug effect? Gut 1991;32:1470-2.

37 O'Mahony S, Anderson N, Nuki G, Ferguson A. Systemic and mucosal antibodies to Klebsiella in patients with ankylosing spondylitis and Crohn's disease. Ann Rheum Dis 1992;51:1296-300. 